\title{
Tectonomagnetic Signals Related to the Seismo-Volcanic Activity in the Izu Peninsula
}

\author{
Yoichi Sasai* and Yoshinobu Ishikawa \\ Earthquake Research Institute, The University of Tokyo, \\ Bunkyo-ku, Tokyo 113, Japan
}

\begin{abstract}
Results of magnetic observations in the eastern Izu Peninsula for the past decade (1980-1990) are summarized. For the period from 1980 to 1983, the geomagnetic total intensity remained constant or slightly increased. Steep increase in the total intensity occurred at three stations (SGH, YSD, and HAT) successively in 1982, when the center of uplift migrated from inland toward east coast. In 1984 a remarkable decrease in the total intensity started on the east-coast upheaval, and lasted until the end of 1986 . Since 1987 two stations across the swarm earthquake zone showed synchronous changes with opposite sign, positive on the north (HAT) and negative on the south (ARA). ARA station is the closest to the 1989 sea-floor eruption site, where the total intensity showed rapid increase within one month including the seismo-volcanic crisis in early July. Magnetic changes due to temperature and stress effects of an active magma reservoir are investigated quantitatively. With the aid of knowledge on magnetic subsurface structure (i.e., Curie point depth) beneath around Izu Peninsula, the cause of magnetic changes is discussed. No prominent long-term magnetic change has been observed along with the inland uplift from 1975 to 1982 . This is because the magma reservoir lies too deep below the Curie point isotherm. However, a few rapid total intensity changes with positive sign have been observed, which were associated with local episodic upheaval. This suggests another cause of uplift: i.e. intrusion of high-pressure and low-temperature fluid into shallow depth. Remarkable decrease over the east coast bulge during 1984-1986 is caused by thermal demagnetization due to hydrothermals dispatched from magma reservoir. The paired anomaly at HAT and ARA for 1987-1988 is also due to thermal demagnetization, which can be regarded as a long-term precursor to the 1989 sea-floor eruption. The change at ARA during and after the seismo-volcanic crisis in July, 1989, is interpreted as piezomagnetic effect due to shallow pressure source with low temperature.
\end{abstract}

\section{Introduction}

A very high tectonic activity has been under way for the past 16 years since the Izu-hanto-oki earthquake of $M 6.9$ in 1974. Major tectonic events were five severe-damage earthquakes, intermittent earthquake swarms and crustal uplift

Received October 31, 1990; Accepted January 25, 1991

* To whom correspondence should be addressed. 
amounting to $50 \mathrm{~cm}$. Even a volcanic eruption took place on the sea floor only $4 \mathrm{~km}$ offshore in July 1989. We started our geomagnetic observations in 1976, just when an anomalous upheaval of $14 \mathrm{~cm}$ or so was found in the north-eastern part of the Peninsula. Repeat magnetic surveys as well as continuous observations of the geomagnetic total intensity have been conducted in the eastern part of the Izu Peninsula, to detect possible changes associated with these tectonic events.

In the 1970's, some remarkable changes related to earthquakes were observed. Repeat surveys revealed a $5 \mathrm{nT}$ change at a survey point very close to the generating fault of the Kawazu earthquake (M5.4) in 1976 (Sasai and Ishikawa, 1977). A few nT changes were found by repeat surveys at two points near the fault of the 1978 Izu-Oshima-kinkai earthquake (M7.0) (Sasai and Ishikawa, 1978). A remarkable precursory magnetic change was first detected by means of continuous observations: the total intensity at Matsuzaki, about $20 \mathrm{~km}$ west of the focal area of the $M 7.0$ quake, suddenly increased by $5 \mathrm{nT}$ in mid-November 1977, two months prior to the main shock (Ohchi et al., 1979). Another precursory change was observed at Kawazu station, two months before the Higashi-Izu earthquake of M4.9 on November 23, 1978. The total intensity decreased down to $-7 \mathrm{nT}$ and jumped up coseismically by $5 \mathrm{nT}$. Kawazu station is located almost above a buried subsidiary fault of the $M 7.0$ earthquake. We presumed that the buried fault slipped aseismically before the $M 4.9$ quake (Sasai and Ishikawa, 1980 a). However, in the case of the 1980 Izu-hanto-toho-oki earthquake of M6.7, we failed to detect coseismic magnetic changes (Sasai and Ishikawa, 1980 b). This earthquake happened to occur about $10 \mathrm{~km}$ offshore. Rikitake et al. (1980) summarized magnetic observations in the Izu Peninsula conducted by Earthquake Research Institute, Tokyo Institute of Technology and Magnetic Observatory of the Japan Meteorological Agency during the 1970's.

Higashi-Izu earthquake of M4.9 is a particular event in the recent seismic history of Izu Peninsula. It can be regarded as the last one in the aftershock sequence of the Izu-Oshima-kinkai earthquake. Only $16 \mathrm{~h}$ after the quake, microearthquakes began to occur east off the Kawanazaki Promontory, Ito City. This is the onset of the most active earthquake swarms in the eastern Izu region which have intermittently taken place for the past 10 years. On the other hand, the seismic activity in the southern half of the Peninsula abruptly turned quiescent since then.

Hypocenters of swarm earthquakes off the east coast arrange in a belt-shaped zone trending WNW to ESE beneath the sea. Repeat leveling surveys and tide gauge records revealed marked land upheaval on the southwestern side of the swarm area. During the period from 1975 to 1978, the center of ground uplift was located in the inland area near Hiekawa Pass, about $10 \mathrm{~km}$ west of the coast line. Recent uplift has a different center, i.e., along the east coast near Yahatano, Ito City. We observed remarkable changes in the total intensity around the uplift area (Sasai and Ishikawa, 1982, 1985; Ishikawa et al., 1988; Sasai, 1989). The time variation of magnetic changes is, however, rather complicated. The cause of magnetic changes should be directly related to the generating mechanism of crustal uplift and swarm earthquakes.

Many authors discussed the possible cause of the anomalous crustal uplift in the eastern Izu Peninsula. The following have been nominated: (1) inflation of a magma chamber at depth, (2) creep dislocation of a deep-seated thrust fault, (3) dilatancy as 
a precursor to a big earthquake, and (4) a sort of inelastic deformation under a critical stress level. These models as well as the overall process of the crustal activity were reviewed and summarized by Tsumura (1977), Shimazaki (1980) and Mogi (1982, 1985). The second hypothesis was rejected because the fault movements of Izu-Oshima-kinkai and Izu-hanto-toho-oki earthquake were not in harmony with the supposed deep-seated faulting. The third one was also abandoned since occurrences of $M 7.0$ and M6.7 quakes did not affect the ongoing upheaval.

A number of small monogenetic volcanos are distributed in the eastern part of the Izu Peninsula on land as well as beneath the sea off the east coast. They are called Higashi-Izu monogenetic volcano group (Aramaki and Hamuro, 1977). The intrusive magma is now regarded as the most probable source for the crustal activity during the past decades, which was dramatically demonstrated by the 1989 sea-floor eruption off Ito City. However, a dilatancy-related phenomenon was definitely observed: i.e., resistivity changes associated with the uplift (Honkura and Taira, 1983). We should not rule out the fourth hypothesis even though it might be a secondary mechanism driven by intrusive magma.

The magnetic data have provided us with a strong evidence for the "magma origin" hypothesis (Sasai and Ishikawa, 1985; Sasai, 1989). Just after the sea floor eruption in 1989, we reinforced continuous observations in coorperation with researchers in other universities. We have now 15 continuously recording proton precession magnetometer stations in the eastern Izu region. Such a magnetometers array is one of the most dense networks for monitoring crustal activity. Results of recent observations will be found elsewhere (Oshiman et al., 1991). In this paper we will present our results mainly for the pre-eruption period from 1980 to 1989.

\section{Magnetic Changes Associated with the Crustal Uplift along the East Coast during 1983-1986}

Figure 1 shows the distribution of magnetic observation points in the eastern part of the Izu Peninsula. Double circles with station codes indicate continuously recording magnetometer stations, while solid circles indicate repeat survey points.

Figure 2 shows total intensity changes as detected by repeat magnetic surveys during the period from July 1984 to September 1986. The hatched area implies the one which showed decrease by more than $2 \mathrm{nT}$. The Geographycal Survey Institute (GSI) reported height changes for almost the same period (May-July, 1984 to May-July, 1986) as shown in Fig. 3 (GSI, 1987). Ito tidal station is located just at the center of the domal bulge. The maximum uplift during that period amounted to $40 \mathrm{~mm}$. The contour line of $20 \mathrm{~mm}$ upheaval roughly coincides with the isomagnetic line of $-2 \mathrm{nT}$ in Fig. 2. The survey point which showed maximum decrease of $-9.6 \mathrm{nT}$ in Fig. 2 is called IKE. It is located near the southwestern side of Omuro-yama Volcano.

In Fig. 4 are shown time variations of geomagnetic total intensity at several survey points in and around the uplift area. At the survey point IKE, we found a remarkable decrease of more than $15 \mathrm{nT}$ in the 3-year period from 1983 to 1986. Repeat magnetic surveys have been conducted with continuously recording proton precession magnetometers, operating during midnight when electric railways as well as natural

Vol. 39, No. 1, 1991 


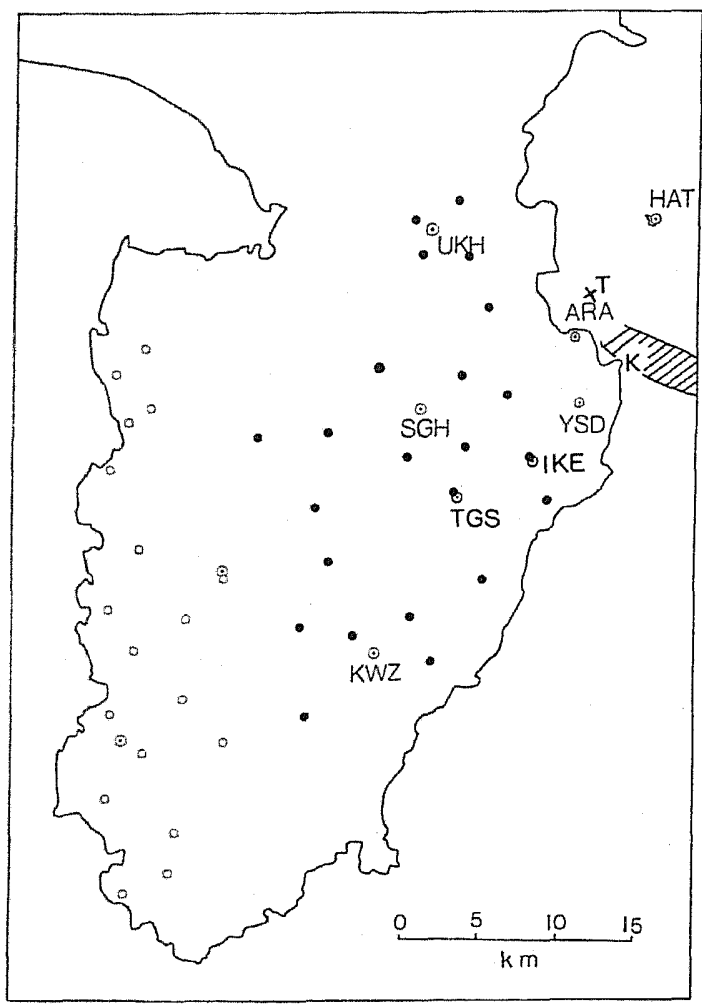

Fig. 1. Distribution of magnetic observation points in the eastern part of the Izu Peninsula before the 1989 sea-floor eruption. T denotes the Teisi Knoll which was formed by the 1989 eruption. The hatched area indicates the swarm earthquakes zone east off the Kawanazaki Promontory denoted by $\mathrm{K}$.

magnetic noises are minimal. This method is rather time-consuming, but guarantees much more reliable results than the traditional one during daytime. Solid and hollow circles in Fig. 4 indicate results from midnight data and daytime ones, respectively. Figure 4 tells us that the decrease in the total intensity becomes obvious since 1983 or 1984.

\section{Total Intensity Changes during the 1980 's by Continuous Observations}

Detailed time variations are seen via continuous observations. Figure 5 shows changes in the total intensity at six stations in the eastern part of the Izu Peninsula during the period from January 1980 to June 1990 . Monthly mean simple differences of nighttime values $(00 \mathrm{~h} 00 \mathrm{~m}-04 \mathrm{~h} 59 \mathrm{~m} \mathrm{LT})$ are plotted in which the reference station is KWZ. Stations YSD, ARA, and IKE belong to the eastern uplift area along the coastline. SGH is located around the western periphery of the uplift area. This station is, however, closer to the earlier center of uplift which was prominent around Hiekawa 


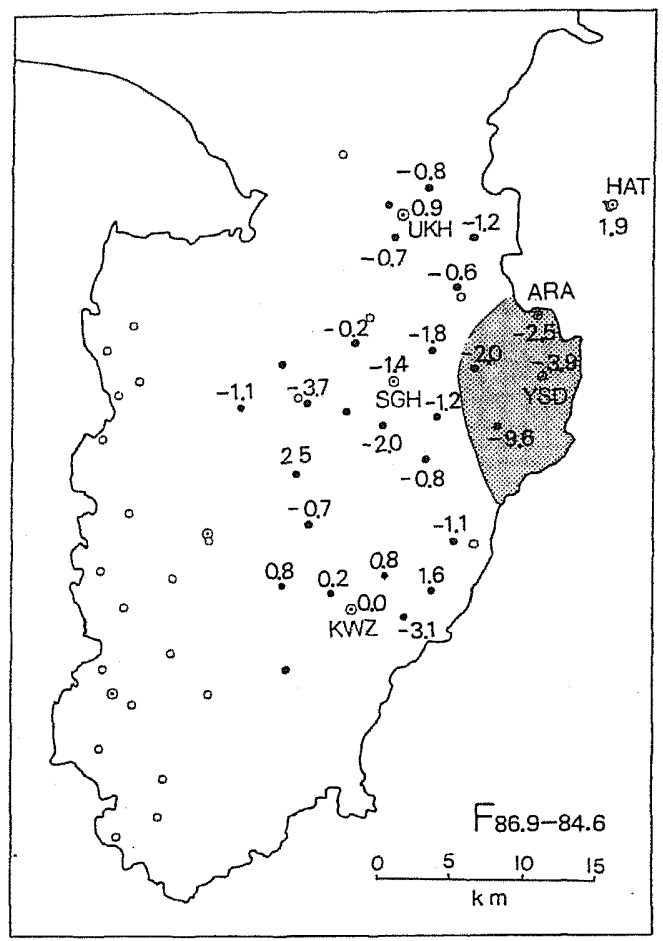

Fig. 2

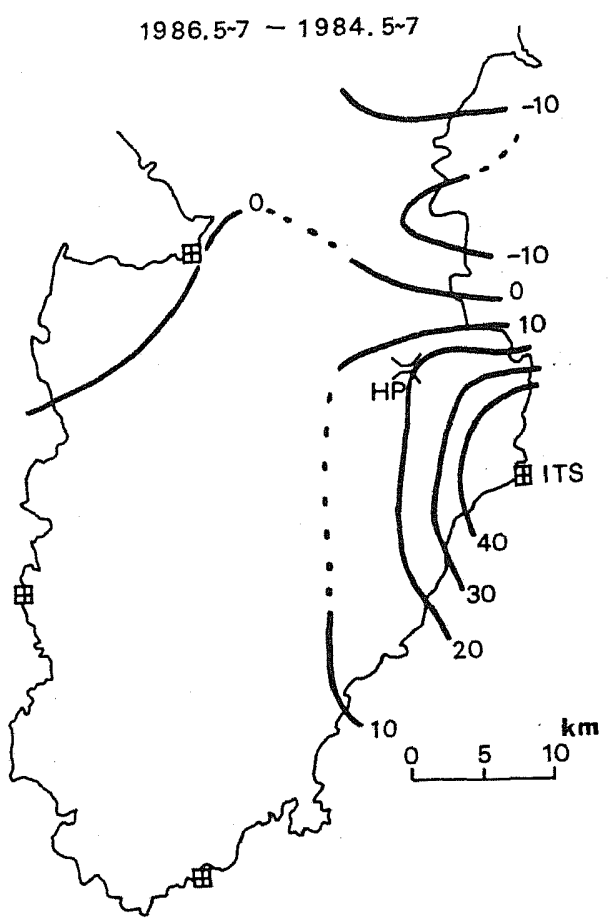

Fig. 3

Fig. 2. Total intensity changes revealed by repeat magnetic surveys during the period from July 1984 to September 1986 . The reference station is KWZ. Unit in $\mathrm{nT}$.

Fig. 3. Height changes during the period from June-July 1984 to June-July 1986 (after GSI, 1987: Contours are drawn by the authors). Unit in cm. Locations of Hiekawa Pass (HP) and Ito tidal station (ITS) are shown.

Pass since 1975 to early 1980 's.

HAT station is located on a tiny island, Hatsushima, about $7 \mathrm{~km}$ northeast of ARA. A tide gauge was installed in 1981. The record shows that this island was also upheaving since 1982 (Kato, 1989). UKH is the only station that is distant from uplift area. Unfortunately this station suffered some artificial disturbances: the long-term declining trend at UKH in Fig. 5 is uncertain. At YSD and SGH the total intensity gradually increased toward the end of 1983 and it turned to steep decrease. At ARA the total intensity remained almost constant during the period from 1980 to 1983 and then began to decrease since 1984. The declining tendency at YSD and SGH ceased in the beginning of 1987.

Since 1987, we started continuous observations at IKE, where remarkable decrease in the total intensity had been detected by repeat surveys. The magnetometer sensor was installed about $200 \mathrm{~m}$ apart from the survey point for the convenience of commercial 


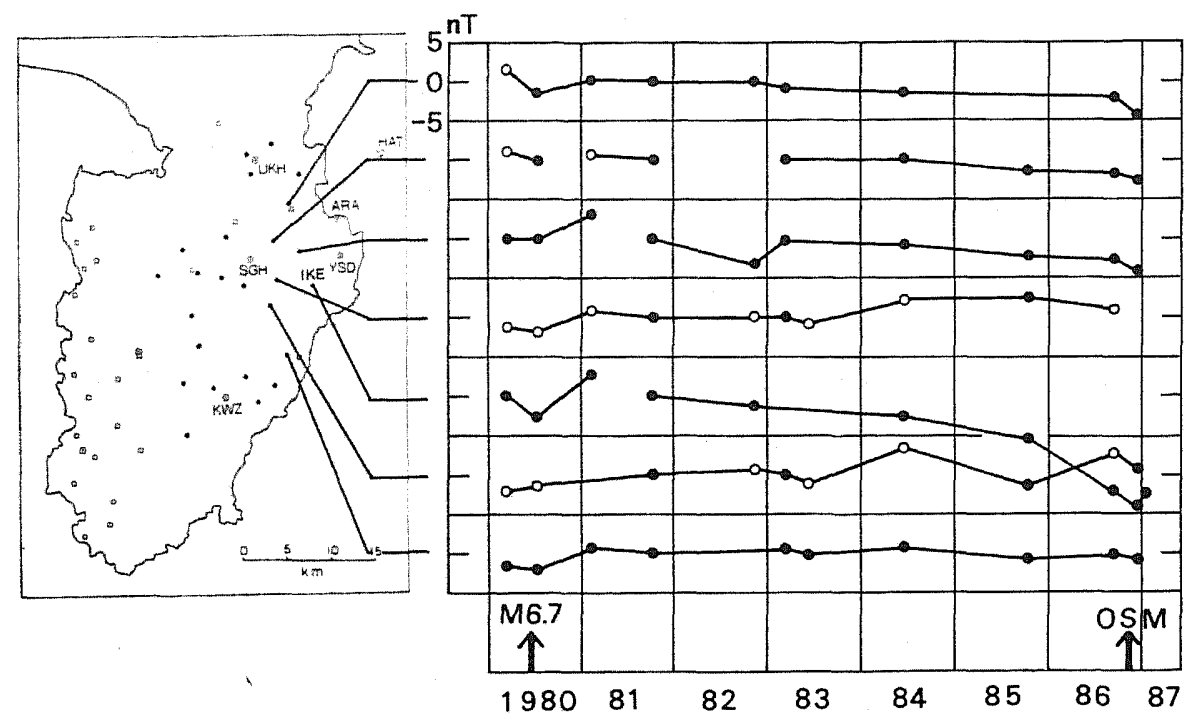

Fig. 4. Results of repeat magnetic surveys at several points in and around the uplift area from 1980 until 1987. The reference station is KWZ.

electric power supply. As shown in Fig. 5, we have a prominent annual change with an amplitude of a few nT at this station. Another magnetometer supplied by solar batteries was then settled at a point only $5 \mathrm{~m}$ from the original survey point in order to investigate the spatial extent of the annual variation. We observed no such changes at the new magnetometer site. The cause of such a localized variation is not clear at present. Disregarding the annual change we find that the total intensity at IKE increased slightly since 1987 in contrast to enormous decrease from 1983 to 1986 . IKE station behaved in a similar way to YSD station, although its variation amplitude was large.

The station ARA continued to decrease even after 1987. On the other hand, the total intensity at HAT began to increase since 1987, where it remained constant during the period from 1983 to 1986 . Synchronous variations at HAT and ARA look like a paired anomaly. This can be regarded as a long-term precursor to the 1989 sea-floor eruption.

The influence of sea-floor eruption is obviously seen at ARA, where the total intensity turned to increase. The decrease in the total intensity seems to have started again at YSD and IKE stations.

According to the tide gauge record at Ito tidal station, the crustal uplift centered around the east coast has continued at an approximately constant rate, i.e. $2.7 \mathrm{~cm} /$ year, since 1978 (Kato, 1989). Time variations of the magnetic field are not so simple as we have seen in Fig. 5. We may distinguish four epochs of geomagnetic variations: (1) January 1980-December 1983: gradual increase with step-like changes in the total intensity at YSD, HAT, and SGH; (2) January 1984-December 1986: steep decrease at YSD, ARA, IKE, and SGH; (3) January 1987-June 1989: stagnation of decrease at YSD, IKE, and SGH, together with a paired positive and negative change at HAT and 


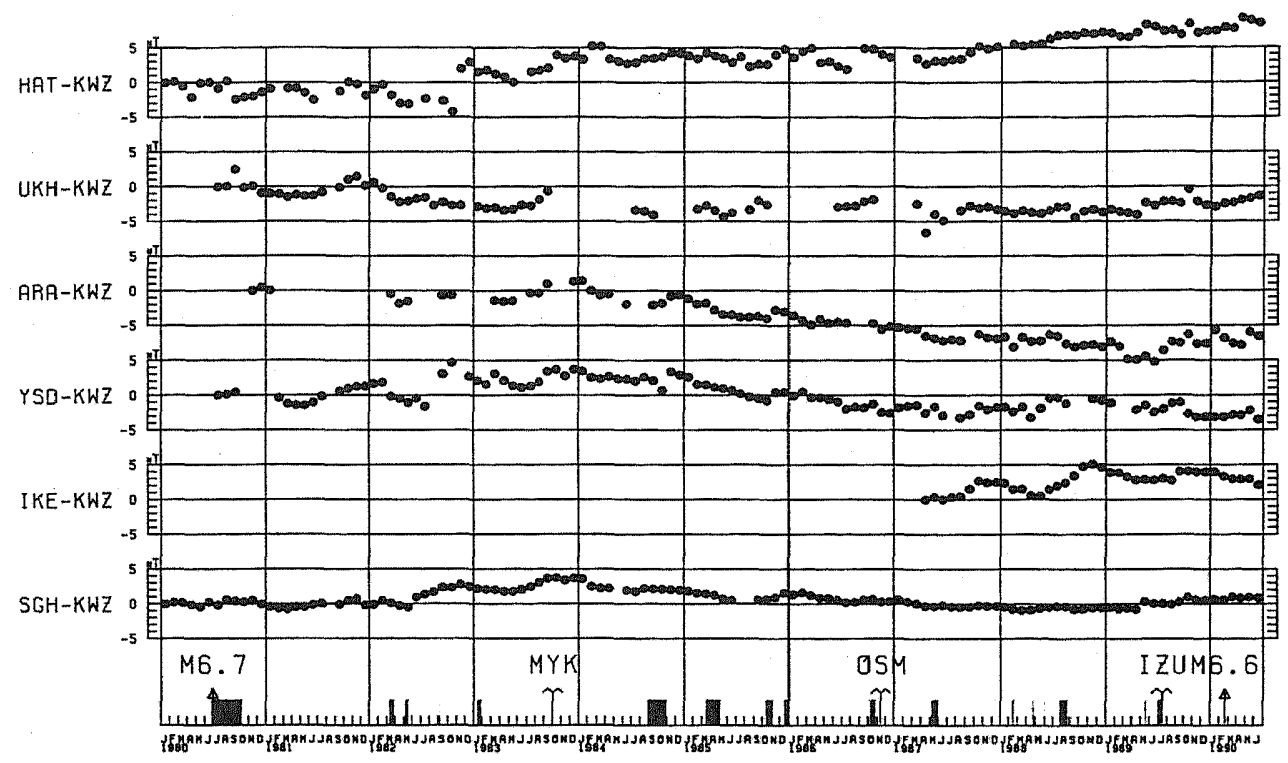

Fig. 5. Monthly means of simple differences of nighttime values between each station and $\mathrm{KWZ}$.

ARA; (4) July 1989-: increase at ARA and gradual decrease at YSD and IKE.

At the bottom of Fig. 5 are indicated occurrences of major tectonic events in and around the Izu Peninsula. They are two damage earthquakes east off the coastline, swarm earthquakes off the Kawanazaki Promontory and volcanic eruptions in the northern part of the Izu-Bonin arc (i.e., the 1983 Miyake-jima, the 1986 Izu-Oshima and the 1989 Izu (Teisi Knoll) eruptions). The locations of the Teisi Knoll and the swarm earthquakes area are shown in Fig. 1. Earthquakes seem to have no close relationship to magnetic changes. However, volcanic eruptions appear to have happened at the turning points of long-term trend in the total intensity variations.

As will be discussed in Sec. 5, long-term magnetic changes are directly controlled by activation or decay of magma reservoirs beneath the eastern Izu Peninsula. Hence an apparent relation between volcanic eruptions and magnetic variations suggests that eruptions at distant volcanos triggered activation of magma under the Izu Peninsula. Such a mechanism is most likely to work as follows: even a slight depression of hydrostatic pressure due to volcanic eruptions at far-field distances stimulates vesiculation of volatiles in an active magma reservoir to cause crustal uplift and hence magnetic change.

Ishii (1989) analyzed vertical deformation data (i.e., leveling and tide gauge records) in the Izu Peninsula. With the aid of a skilful technique for spatio-temporal interpolation, he presented contour maps of yearly vertical displacements shown for every half year. He pointed out that: (a) during the period from January 1980 to June 1982, the peak position of upheaval was located inland close to the earlier center around Hiekawa Pass; (b) within the period from June 1982 to January 1983, the uplift center shifted toward the east coast around Ito tidal station; (c) the upheaval rate was accelerated

Vol. 39, No. 1, 1991 
since 1987. Three epochs (a), (b), and (c) almost coincide with the first three epochs (1), (2), and (3) of magnetic variations in Fig. 5.

Sasai and Ishikawa (1985) noticed steep increase in the total intensity observed at three stations in 1982. These magnetic events are obviously seen in Fig. 5: i.e., at SGH in May, at YSD in September and at HAT in November, 1982. A close inspection around sensors at SGH and YSD could not specify any obstacles to produce such disturbances. The change at HAT is, however, somewhat unreliable because this station was affected by new facilities constructed during that year. Tears in the baseline values as far as we could identify were corrected, though. These magnetic changes happened in association with episodic uplift events propagating from inland toward east coast. According to leveling surveys, Hiekawa Pass rose by $2 \mathrm{~cm}$ relative to Ito City in May-June, and then Ito City upheaved by the same amount in November-December, 1982 (GSI, 1983). Tide gauge record indicates that Hatsushima Island showed steep rise in the end of 1982 (Kato, 1989). These successive events correspond to migration of the uplift center in the early stage of the epoch (b) in Ishii's (1989) analysis. It is noteworthy that episodic upheavals in 1982 accompanied increase in the total intensity.

We have two more examples of spatial pattern of total intensity change as revealed by repeat surveys in the earlier stage of our observations. In Fig. 6 is reproduced the result of repeat surveys during the period from May-June to November, 1976 (Sasai and Ishikawa, 1977). The uplift area centered around Hiekawa Pass expanded westward during that period (GSI, 1977). The newly upheaved area was included within the positive change region in Fig. 6. An isolated positive change in the south was the one accompanied with the Kawazu earthquake of M5.4 in August, 1976. Ohshiman et al. (1983) frequently repeated precise magnetic surveys along an N-S traverse running on the western side of the inland bulge from December 1978 to March 1982. They found opposite signs of magnetic change across the upheaval during that period, which was again positive on the south side and negative on the north.

Let us have a close look at magnetic changes before and after the sea-floor eruption. Figure 7 shows total intensity changes at eight stations during the period from January 1987 to June 1990. They are 5-day means of simple differences of nighttime values relative to KWZ. IK2 was established at a survey point only $200 \mathrm{~m}$ distant from IKE station to investigate the spatial extent of the seasonal change observed at IKE. TGS was located $5 \mathrm{~km}$ west of IKE.

The paired anomalous change, positive at HAT and negative at ARA, is prominent in 1987 and 1988. The reversal of magnetic variation at ARA began just before the seismo-volcanic activity in early July of 1989 . No change was, however, observed at HAT during that period. This suggests that the cause of magnetic change at ARA after the Teisi Knoll eruption is different from that of the paired anomaly in 1987-1988.

In Fig. 7 we find another group of stations, i.e., IKE, IK2, and TGS, which show increase in the total intensity during the latter half of 1988. Apart from seasonal changes, the total intensity values at IKE and IK 2 were biased by 2 or $3 \mathrm{nT}$ during the period from 1987 to 1988. At TGS the total intensity continued to increase even in 1989. Such localized changes have been found recently by a dense network of magnetometers (Oshiman et al., 1991). 


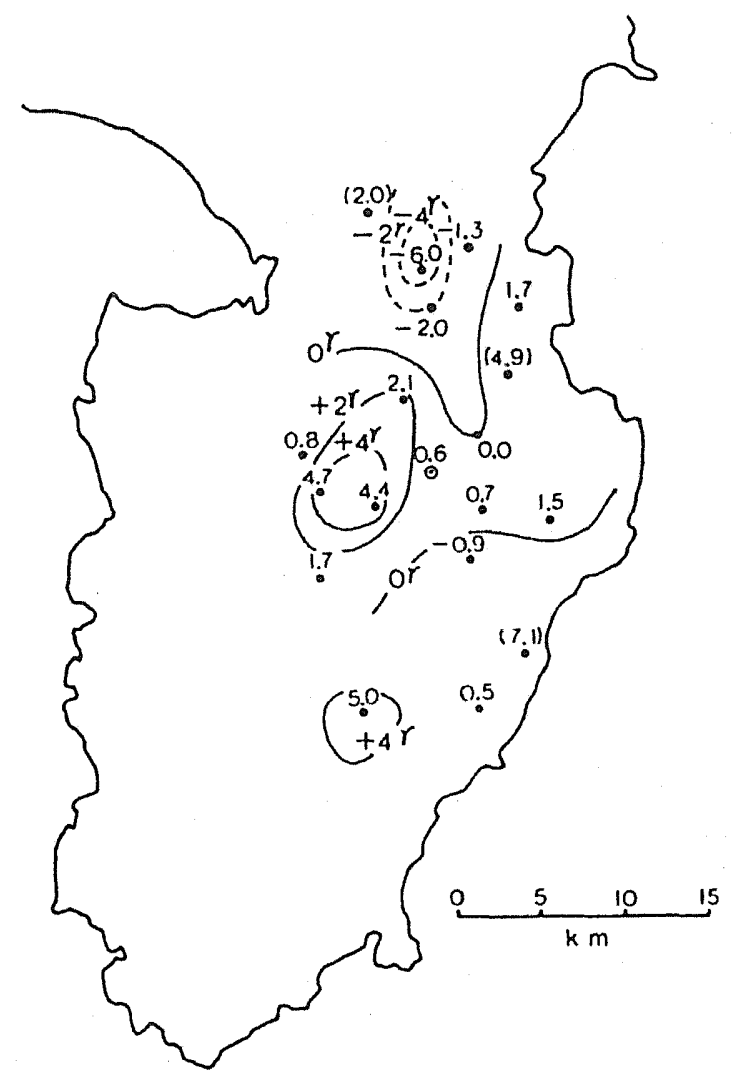

Fig. 6. Changes in the total intensity in unit of gammas (nT) during the period from May-June to November, 1976 (reproduced from Sasai and Ishikawa, 1977). The reference station is Kanozan Geodetic Observatory of GSI, about $100 \mathrm{~km} \mathrm{NE}$ of Izu region. Values in the parentheses suffered artificial disturbances.

\section{Magnetic Changes Produced by an Active Magma Reservoir}

Hagiwara (1977 a) proposed that the inflation of a magma reservoir was the most probable cause of the domal uplift in the earlier stage of the crustal activity in the 1970 's. He theoretically derived the gravity change associated with the Mogi model (Mogi, 1958) and compared it with results of precise gravity surveys. The gravity change rate along with the uplift in the inland area has the free-air gradient, which is favorable to volcanic gas as the pressure source. We have already seen in Fig. 2 that the domal uplift centered around the east coast accompanied a remarkable decrease in the geomagnetic total intensity. This naturally makes us imagine that thermal demagnetization should occur around a magma reservoir. Both gravity and magnetic data seem to support existence of intrusive magma as the driving force of crustal

Vol. 39, No. 1, 1991 


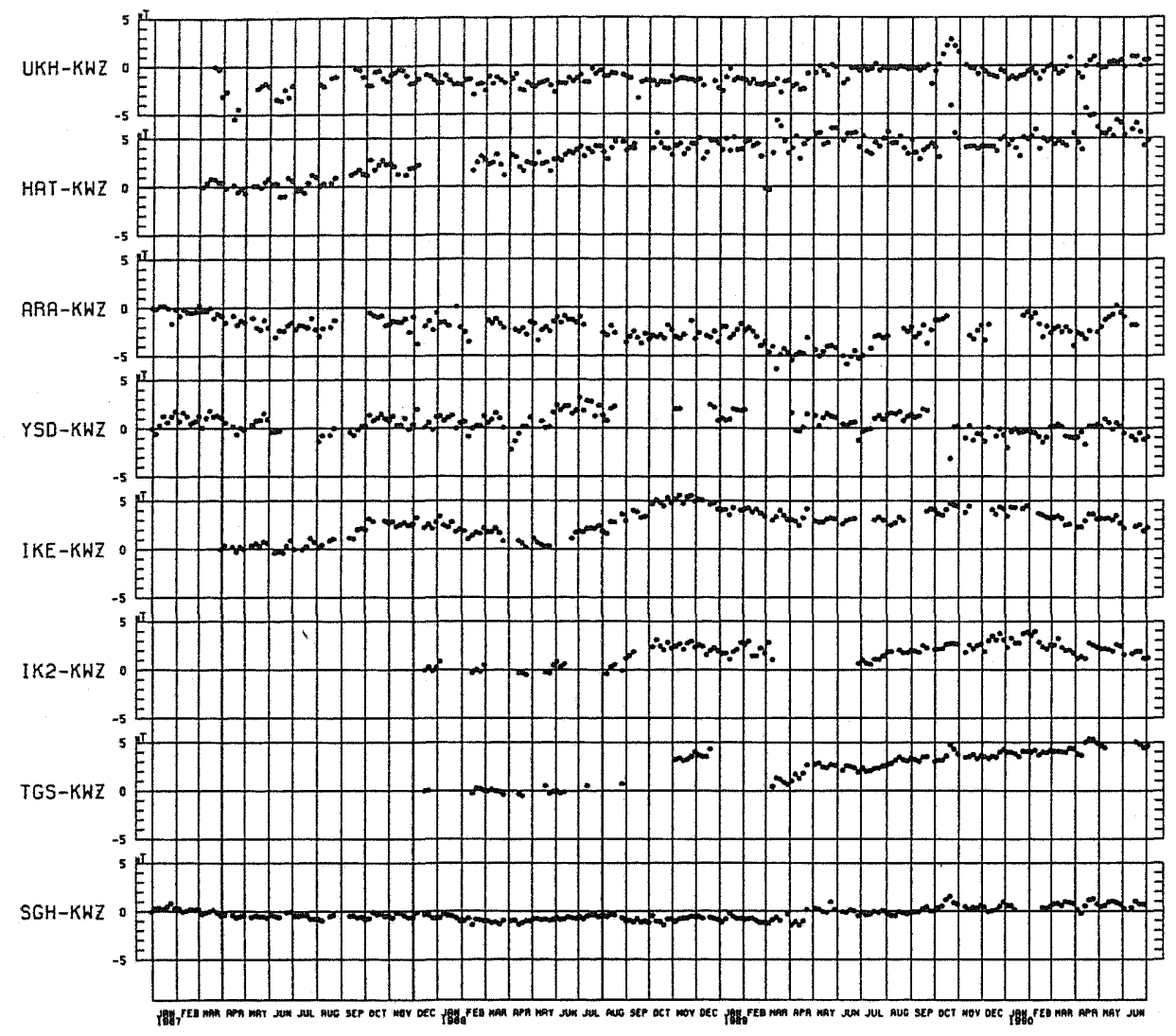

Fig. 7. Total intensity changes in the eastern Izu region during the period from January 1987 to June 1990 . Five-day means of nighttime differences are plotted.

deformation in the eastern Izu Peninsula. However, total intensity changes associated with crustal uplift are rather confusing. There are two opposite types of magnetic changes. The one is wide-spread, long-lived and negative on the southern side of upheaval, while the other is rather localized, rapid and positive on the southern side. In order to search for the cause of magnetic changes we will estimate the influences of an active magma reservoir on the magnetic field.

Thermal demagnetization effectively proceeds if hydrothermals and/or magma itself penetrate into cracks around the magma chamber. Piezomagnetic changes are also anticipated owing to inflation or deflation of the reservoir. We assume a spherical region as a thermally demagnetized area due to hot magma. We also suppose the stress field of a center of dilatation in an elastic half space (i.e., the Mogi model) as the stress effect of the magma reservoir.

Next we require knowledge of subsurface magnetic structure beneath the Izu region. A few sets of air-borne magnetic data are available over the southern Kanto and Tokai district. Some authors analyzed these data to present models of crustal magnetization 
(Ishikawa and Yukutake, 1982; Okubo, 1984; Nakagawa, 1986). The most comprehensive study is the Curie point depth analysis beneath the Japanese Islands (Okubo, 1984). The upper part of the Earth's crust can be regarded, as a first order approximation, to be uniformly magnetized from the surface to a depth of Curie point isotherm. The Curie depth in the eastern Izu Peninsula is very shallow: i.e., only 8 or $9 \mathrm{~km}$.

Hagiwara (1977 a) applied the Mogi model to elevation change data in the 1970's. He obtained the following model parameters: the depth of the center of source sphere $D=10 \mathrm{~km}$, its radius $a=2 \mathrm{~km}$, and the maximum uplift $\Delta h=15 \mathrm{~cm}$. As for the domal uplift along the east coast during the 1980's, we have no data on the eastern half of uplift area. If we assume that the true uplift center lies around Ito tidal station, we obtain nearly the same values for model parameters as those by Hagiwara (1977a). In that case, even the medium surrounding the reservoir has a temperature higher than the Curie point; we cannot expect any changes in the magnetic field owing to thermal demagnetization.

However, uncertainty remains on the actual value of the Curie depth as determined by the Curie point depth analysis (Okubo, 1986). Moreover, Ishikawa and Yukutake (1982) and Nakagawa (1986) presented different results by means of ordinary techniques for interpretation of magnetic anomalies; strongly magnetized material exists beneath the Sagami trough and Tanzawa mountains, adjacent to the Izu Peninsula. Depth of these magnetic bodies is far greater than the results of Curie depth analysis. Now let us assume that the deeper portion of the crust is magnetized even beneath the Izu region: thermal demagnetization should occur below the depth of $10 \mathrm{~km}$ or so.

Figure 8(a) shows the total intensity changes on the ground surface when a spherical region of radius $2 \mathrm{~km}$ at a depth of $10 \mathrm{~km}$ loses its magnetization by $1 \mathrm{~A} / \mathrm{m}$. The center of the sphere is located just below the center of the square frame, of which the side length is $20 \mathrm{~km}$. The magnetic dip is assumed to be $46^{\circ}$, which is an average value in the Izu region. The same anomaly pattern would be obtained for any arbitrary spherical shell with an appropriate (negative) magnetization.

Piezomagnetic change associated with the Mogi model was solved numerically by Davis (1976) and analytically by Sasai (1979). Both calculations gave different results and hence were reexamined (Suzuki and Oshiman, 1990; Sasai, 1991). An error was found for the point source case in Sasai's (1979) result. Sasai (1991) presented analytic expressions for finite spherical source. Figure 8(b) shows computed piezomagnetic changes due to the Mogi model when the source sphere lies beneath the Curie point isotherm. Model parameters are as follows: $D=10 \mathrm{~km}, a=2 \mathrm{~km}, \Delta h=10 \mathrm{~cm}$, and the Curie depth $H=8 \mathrm{~km}$. A strong magnetization $J=5 \mathrm{~A} / \mathrm{m}$ and the stress sensitivity $\beta=2 \times 10^{-4} \mathrm{bar}^{-1}$ are assumed. The decrease in the total intensity prevails all over the surface, which resembles the effect of thermal demagnetization. However, the amount of magnetic change is too small as compared with the observations.

In Fig. 8(c) are depicted total intensity changes at the earth's surface for the same model parameters as those in Fig. 8(b), only except for the Curie depth $H=20 \mathrm{~km}$. In the case that the pressure source is included in the magnetized region, the total intensity increases above the southern half of upheaved area. It seems as if the cooling, and hence remagnetization, took place in the magma reservoir. The transition from Fig. 8 (b) to (c) occurs rapidly when the Curie depth $H$ increases to intersect the spherical

Vol. 39 , No. 1, 1991 


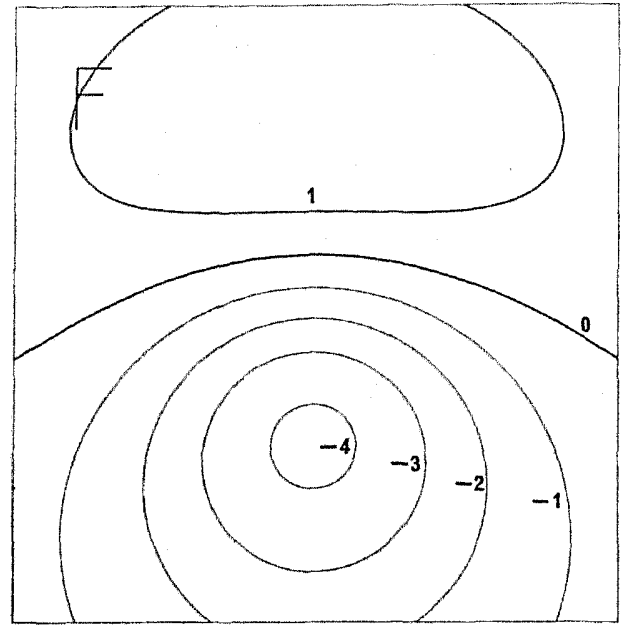

(a)

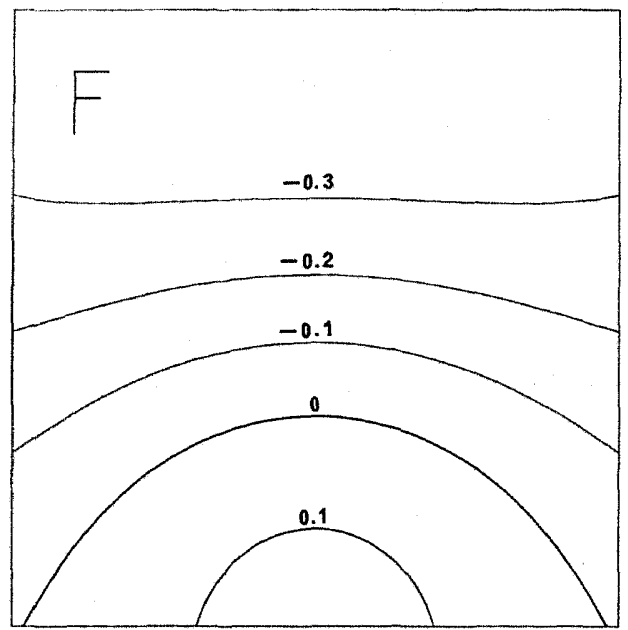

(b)

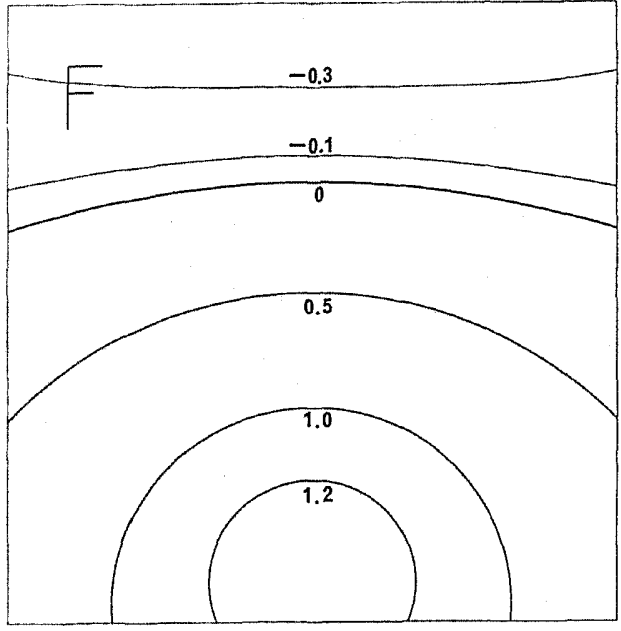

(c)

Fig. 8. (a) Total intensity changes due to a thermally demagnetized sphere. (b) Piezomagnetic changes due to the Mogi model, when the source sphere lies below the Curie point isotherm. (c) Piezomagnetic changes due to the Mogi model, when the source sphere is included within the magnetized region.

source. For $H=D$, the anomaly pattern is similar to Fig. 8(c), but its intensity becomes greater. Anyway, this feature in Fig. 8(c) is opposite in sign to the observation in Fig. 2 , but favorable to the pattern in Fig. 6.

\section{Discussion}

Sasai and Ishikawa (1985) and Sasai (1989) discussed the relationship between magnetic changes and the crustal uplift in the Izu Peninsula on the basis of piezomagnetic model calculations. Their arguments depend on some previous modeling works, some of which were recently found erroneous as was the case of the Mogi model. We are 
now reexamining earlier works on piezomagnetic changes due to dyke formation. We will discuss here on the cause of the magnetic changes associated with the seismo-volcanic activity in the eastern Izu Peninsula with the aid of model calculations in the previous section.

From surface deformation data we may presume three isolated magma sources beneath the eastern Izu Peninsula: (A) a reservoir below the inland area around Hiekawa Pass which caused domal uplift during 1975-1982 (Hagiwara, 1977 a); (B) a reservoir beneath the east coast around Ito tidal station which is responsible for another domal uplift since 1978 until present (Ishii, 1989); (C) intrusive dyke swarm elongated in the WNW-ESE direction around Kawanazaki Promontory (Tada, 1983).

The decrease in the total intensity during the 3-year period from 1984 to 1986 should have been caused by the reservoir B. This change is difficult to explain in terms of piezomagnetism. Thermal demagnetization is favorable to interpret this predominant magnetic change. According to the Curie depth analysis, the Curie point isotherm is shallower than the reservoir B. We may imagine that the demagnetized region expanded upward above the reservoir. The Curie point isotherm should have upheaved convexly. Thus a uniformly demagnetized spherical segment as shown in Fig. Al is an appropriate source for the observed magnetic change. The magnetic field due to a spherical segment is rather difficult to compute in spite of its simple shape. The formula is given in the Appendix.

Figure 9 shows one of thermal demagnetization models to explain the decrease in the total intensity during 1984-1986. This gives surface distribution of total intensity changes due to a spherical segment demagnetized by $1 \mathrm{~A} / \mathrm{m}$. Its geometry is as follows: depth of the center of the sphere $D=12 \mathrm{~km}$, its radius $a=6 \mathrm{~km}$ and the demagnetized portion from top of the sphere down to the thickness $h=1 \mathrm{~km}$. The coastline and magnetic stations as well as the horizontal position of the periphery of the spherical segment are depicted in Fig. 9. We have to shift the center of the demagnetized spherical segment northward from the uplift center to obscure the positive region out of land. This model roughly explains overall features in Fig. 2. However, the sign is opposite at ARA; a spheroidal segment elongated in the N-S direction would be suitable for best-fit. The outstanding decrease at IKE is rather difficult to explain by such a simple shape of magnetic source. Some special situation should be considered around this station. A possibility is some enhancement effect of piezomagnetic field due to local inhomogeneity of magnetization and/or stress (e.g., Oshimann, 1990).

Long-term changes associated with the inflation of the reservoir A were not clear at SGH since 1976 to 1982 . This is most probably because the reservoir A lies below the Curie depth to produce no thermal demagnetization effect and also because the pressure source is located too deep to yield appreciable piezomagnetic field. As for the reservoir B, the situation had been the same as A until 1984, when hydrothermals came up to the shallow portion of the crust to cause thermal demagnetization. Decrease in the total intensity due to B reservoir started about one year later than the migration of uplift center in early 1983 . Such retardation is reasonably interpreted by fluid diffusion through porous media. Expansion of hydrothermal fluid ceased for some reason in the end of 1986. The eruption of Izu-Oshima Volcano in 1986 should have affected the magmatic activity beneath Izu Peninsula.

Vol. 39, No. 1, 1991 


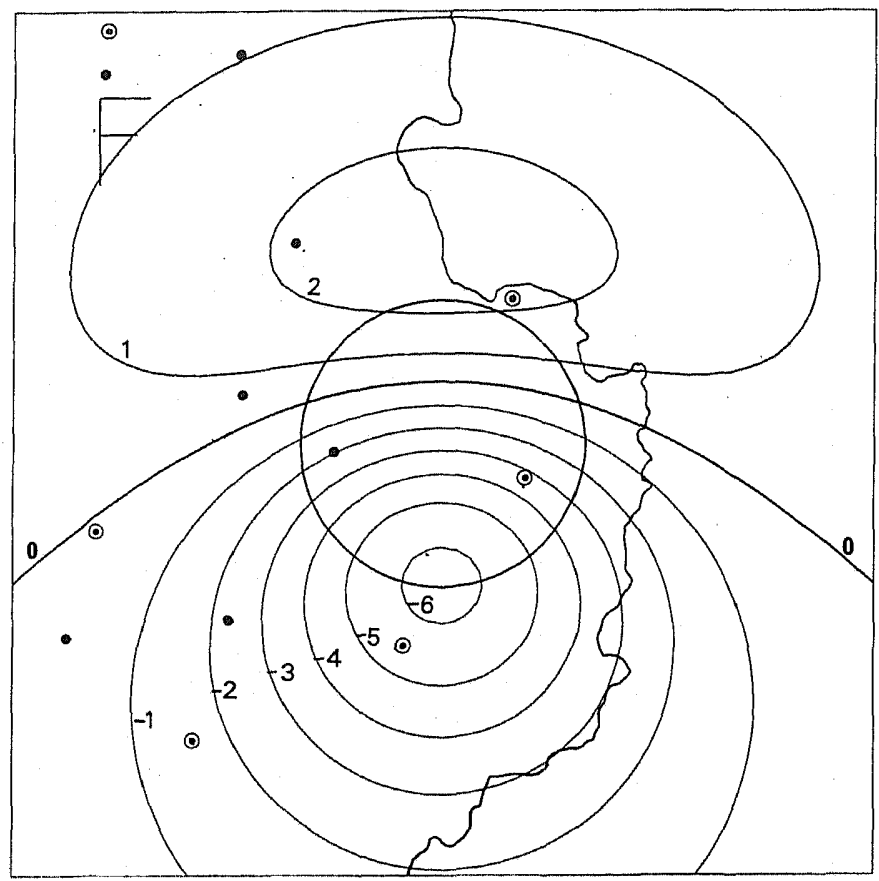

Fig. 9. Total intensity changes due to a demagnetized spherical segment beneath around Ito City. Unit in nT. The top of the segment is at a depth of $6 \mathrm{~km}$, while its bottom at $7 \mathrm{~km}$. The circle indicates its periphery.

The total intensity at ARA continued to decrease after 1987, while that at HAT began to increase. This change should be related to the dyke swarm $C$. Taking account of Fig. 8(a), we may ascribe this paired change to thermal demagnetization somewhere at depth between the two stations. Dyke-like intrusion of magma has been surmised by many authors to have taken place along the linear arrangement of swarm earthquakes off the Kawanazaki Promontory (e.g., Tada, 1983; Sasai and Ishikawa, 1985). Horizontal distance across the earthquake zone has been extending for the past decades (GSI, 1990). Unlike the almost constant upheaval at Ito tidal station, the uplift at Hatsushima Island occurred intermittently in 1982 and 1987 (Kato, 1989), when horizontal extension was also prominent (GSI, 1990). This suggests that the upheaval at Hatsushima Island is mainly caused by swelling of the ground surface on both sides of dyke intrusion. Magnetic changes are dominant only at HAT and ARA. This implies that thermal demagnetization occurred at a shallower depth between the two, probably on the northern side away from the earthquake zone. However, the size and position of the demagnetized area are ambiguous owing to lack of data.

The magnetic change at ARA during the seismo-volcanic crisis in July, 1989, is hardly explainable in terms of temperature effect. ARA is located $4 \mathrm{~km}$ southeast of the eruption site, Teisi Knoll. If a substantial volume suffered thermal demagnetization beneath Teisi Knoll, the total intensity at ARA should have decreased, which is 
contrary to the observation. Another possibility is the appearance of a hot region on the south side of ARA. This is also rejected, because we observed no corresponding decrease in the total intensity at YSD and IKE.

Now let us recall Fig. 8(c). We may expect increase in the total intensity if a dilatation source lies beneath ARA. The pressure source is not necessarily a big sphere such as a magma chamber. Sasai (1986) proposed the multiple tension-crack model, which was an extension of the multiple Mogi model originally given by Hagiwara (1977b). The elastic field associated with the multiple tension-crack model can be calculated by superposing that of a single microcrack with the weight of Gaussian distribution. If cracks are randomly oriented in every direction, its elastic field is equivalent to that of an assemblage of small spherical pressure sources (Sasai, 1986). This can be realized when highly pressurized but low-temperature fluid penetrates into shallower depth to expand crevices of rocks. Then the piezomagnetic change should be quite similar to that of the Mogi model.

We will briefly review the crustal deformation data accompanied with the 1989 seismo-volcanic activity in July. Tsuneishi (1990) developed and installed an automatically measuring geodimeter system along a line connecting Hatsushima Island and Ito City since April, 1989. He detected an extension of $22 \mathrm{~cm}$ accompanying swarm earthquakes in early July. Frequent leveling surveys were conducted on a route along the east coast, which brought to light an upheaval up to $10 \mathrm{~cm}$ before the sea-floor eruption (GSI, 1990). The maximum height change was found near around ARA. Okada and Yamamoto (1991) analyzed these data together with their continuous observations of tiltmeters to present a unified model for crustal deformation during the 1989 activity. Their model consists of an E-W-trending shear fault of the $M 5.5$ earthquake (F3) and two tensile faults (F1 and F2) beneath Teisi Knoll stretching southeastward. They ascribed most of the prominent surface deformations to opening of the tensile fault $F 2$, which grew upward during the first 11 days of July 1989.

Unfortunately, we had some instrumental trouble at ARA for a one-week period including the $M 5.5$ quake on July 9. Total intensity change during the recording gap was about $1 \mathrm{nT}$. As shown in Fig. 6, the increase in the total intensity at ARA was attained within a month since the end of June. The time variation of magnetic field during the first half of July seems harmonious with the growth of the F2 fault in Okada and Yamamoto's (1991) scenario, but it lasted until the end of July. The magnetic change in the post-eruption stage looks as if it were accompanied with any diffusion process. Penetration of high-pressure fluid is the most likely cause. Ground water and/or volcanic gas might have played a significant role in the crustal uplift in the eastern Izu Peninsula, as has been discussed by Tsuneishi $(1990,1991)$.

It should also be noticed that the turnover of magnetic trend at ARA started slightly before the swarm activity. Prediction-error filtering would clarify more details of the on-going process (Tanaka et al., 1978; Davis et al., 1979). Piezomagnetic calculations are also our future subject to evaluate the effect of inclined shear and tensile faults according to Okada and Yamamoto's (1991) model, as well as that of the shallow pressure sources based on the multiple tension-crack model.

We are greatly indebted to many local people who have supported us to maintain continuous

Vol. 39, No. 1, 1991 
observations at each station for the past decades. Discussions with Naoto Oshiman, Hisashi Utada, Yoshimori Honkura, and Yoshikazu Tanaka were very helpful. Yukimasa Tsuneishi and Yoshimitsu Okada kindly showed their preprints and gave us useful suggestions. We also acknowledge Professors Yukio Hagiwara, Takeshi Yukutake, and Ichiro Murata for their encouragement throughout the study.

\section{REFERENCES}

Aramaki, S. and K. Hamuro, Geology of the Higashi-Izu monogenetic volcano group, Bull. Earthq. Res. Inst., Univ. Tokyo, 52, 235-278, 52, 1977 (in Japanese with English abstract).

Davis, P. M., The computed piezomagnetic anomaly field for Kilauea volcano, Hawaii, J. Geomag. Geoelectr., 28, 113-122, 1976.

Davis, P. M., F. D. Stacey, C. J. Zablocki, and J. V. Olson, Improved signal discrimination in tectonomagnetism: discovery of a volcanomagnetic effect at Kilauea, Hawaii, Phys. Earth Planet. Inter., 19, 331-336, 1979.

Eason, G., B. Noble, and I. N. Sneddon, On certain integrals of Lipschitz-Hankel type involving products of Bessel functions, Philos. Trans. R. Soc. London, Ser. A, 247, 529-551, 1955.

Geographical Survey Institute, Crustal deformation in the central part of Izu-Peninsula (2), Rep. Coord. Comm. Earthq. Predict., 17, 59-64, 1977 (in Japanese).

Geographical Survey Institute, Crustal movement in and around Izu Peninsula, Rep. Coord. Comm. Earthq. Predict., 30, 146-157, 1983 (in Japanese).

Geographical Survey Institute, Crustal movement in the Izu region, Rep. Coord. Comm. Earthq. Predict., 37, 224-242, 1987 (in Japanese).

Geographical Survey Institute, Crustal movements in the Izu Peninsula, Rep. Coord. Comm. Earthq. Predict., 43, 227-252, 1990 (in Japanese).

Hagiwara, Y., The Mogi model as a possible cause of the crustal uplift in the eastern part of Izu Peninsula and the related gravity change, Bull. Earthq. Res. Inst., Univ. Tokyo, 52, 301-309, 1977 a (in Japanese with English abstract).

Hagiwara, Y., Matsushiro uplift as a multiple Mogi model, J. Geod. Soc. Jpn., 23, 25-35, 1977 b (in Japanese with English abstract).

Honkura, Y. and S. Taira, 1983, Changes in the amplitudes of short-period geomagnetic variations as observed in association with crustal uplift in the Izu Peninsula, Japan, Earthq. Predict. Res., 2, 115-125, 1983.

Ishii, H., Recent abnormal uplift on the Izu Peninsula (1980-1988), Bull. Earthq. Res. Inst., Univ. Tokyo, 64, 313-324, 1989 (in Japanese with English abstract).

Ishikawa, Y., T. Nakano, and Y. Sasai, Total field changes associated with the anomalous crustal uplift in the Izu Peninsula (1984-1986), Proc. Conductivity Anomaly Symposium (1988), CA Group, 189-194, 1988 (in Japanese).

Ishikawa, Yu. and T. Yukutake, Geomagnetic anomalies over the Fossa Magna region in central Japan, J. Geomag. Geoelectr., 34, 551-570, 1982.

Kato, T., Vertical crustal movements in Japan as deduced from tidal records (1951-1987), Rep. Coord. Comm. Earthq. Predict., 41, 498-520, 1989 (in Japanese).

Mogi, K., Relations between the eruptions of various volcanoes and the deformations of the ground surfaces around them, Bull. Earthq. Res. Inst., Univ. Tokyo, 36, 99-134, 1958.

Mogi, K., Izu Peninsula, Chapter 4, in Earthquake Prediction in Japan, pp. 180-250, Science Co., 
Ltd., Tokyo, 1982 (in Japanese).

Mogi, K., Earthquake Prediction, Academic Press, Tokyo, 355 pp., 1985.

Nakagawa, I., Study of regional magnetic anomalies over the central Japan by use of geomagnetic terrain correction technique, Ph. D. thesis, Univ. Tokyo, 253 pp., 1986.

Ohchi, K., N. Ijichi, M. Kuwashima, and M. Kawamura, Geomagnetic total force intensity variation associated with the Izu-Oshima Kinkai earthquake, 1978, Mem. Kakioka Mag. Obs., 18, 55-64, 1979 (in Japanese with English abstract).

Ohshiman, N., Y. Sasai, Y. Ishikawa, Y. Honkura, and H. Tanaka, Local changes in the geomagnetic total intensity associated with crustal uplift in the Izu Peninsula, Earthq. Predict. Res., 2, 209-219, 1983.

Okada, Y. and E. Yamamoto, The 1989 seismo-volcanic activity off Ito in the Izu Peninsula as revealed by crustal movement data, Earth Monthly, 13, 95-102, 1991 (in Japanese).

Okubo, Y., Results of Curie point analysis in Japanese Islands, Geology News, Geological Survey of Japan, No. 362, 12-17, 1984 (in Japanese).

Okubo, Y., Geothermal exploration and Curie point analysis, Geotherm. Energ., 11, 369-394, 1986 (in Japanese).

Oshiman, N., Enhancement of tectonomagnetic change due to non-uniform magnetization in the earth's crust-two-dimensional case studies, J. Geomag. Geoelectr., 42, 607-619, 1990.

Oshiman, N., Y. Honkura, Y. Sasai, Y. Ishikawa, H. Utada, S. Koyama, Y. Tanaka, and T. Yukutake, Magnetometer array observation in the north-eastern Izu region after the Teisi Knoll seafloor eruption in 1989, J. Phys. Earth, 39, 321-328, 1991.

Rikitake, T., The distribution of magnetic dip in Ooshima (Oo-sima) Island and its change that accompanied the eruption of Volcano Mihara, 1950, Bull. Earthq. Res. Inst., Univ. Tokyo, 29, 161-181, 1951.

Rikitake, T., Y. Honkura, H. Tanaka, N. Ohshiman, Y. Sasai, Y. Ishikawa, S. Koyama, M. Kawamura, and $\mathrm{K}$. Ohchi, Changes in the geomagnetic field associated with earthquakes in the Izu Peninsula, Japan, J. Geomag. Geoelectr., 32, 721-739, 1980.

Sasai, Y., The piezomagnetic field associated with the Mogi model, Bull. Earthq. Res. Inst., Univ. Tokyo, 54, 1-29, 1979.

Sasai, Y., Multiple tension-crack model for dilatancy: surface displacement, gravity and magnetic change, Bull. Earthq. Res. Inst., Univ. Tokyo, 61, 429-473, 1986.

Sasai, Y., Tectonomagnetism in southern Kanto and Tokai district, central Japan, J. Geod. Soc. Jpn., 35, 227-242, 1989.

Sasai, Y., Piezomagnetic field associated with the Mogi model revisited: analytic solution for finite spherical source, J. Geomag. Geoelectr., 43, 21-64, 1991.

Sasai, Y. and Y. Ishikawa, Changes in the geomagnetic total force intensity associated with the anomalous crustal activity in the eastern part of the Izu Peninsula (1), Bull. Earthq. Res. Inst., Univ. Tokyo, 52, 173-190, 1977 (in Japanese with English abstract).

Sasai, Y. and Y. Ishikawa, Changes in the geomagnetic total force intensity associated with the anomalous crustal activity in the eastern part of the Izu Peninsula (2)-The Izu-Oshima-kinkai earthquake of 1978-, Bull. Earthq. Res. Inst., Univ. Tokyo, 53, 893-923, 1978 (in Japanese with English abstract).

Sasai, Y. and Y. Ishikawa, Tectonomagnetic event preceding a $M 5.0$ earthquake in the Izu Peninsula-Aseismic slip of a buried fault ?, Buli. Earthq. Res. Inst., Univ. Tokyo, 55, 895-911, 1980 a.

Sasai, Y. and Y. Ishikawa, Changes in the geomagnetic total force intensity associated with the 
anomalous crustal activity in the eastern part of the Izu Peninsula (3)-The East off Izu Peninsula earthquake of 1980-, Bull. Earthq. Res. Inst., Univ. Tokyo, 55, 1101-1113, 1980 b (in Japanese with English abstract).

Sasai, Y. and Y. Ishikawa, Changes in the geomagnetic total force intensity associated with the anomalous crustal activity in the eastern part of the Izu Peninsula (4)-Anomalous change observed in the north-eastern area in 1981-, Bull. Earthq. Res. Inst., Univ. Tokyo, 57, 739-757, 1982 (in Japanese with English abstract).

Sasai, Y. and Y. Ishikawa, Changes in the geomagnetic total force intensity associated with the anomalous crustal activity in the eastern part of the Izu Peninsula (5)-1982-1983 Off-Kawanazaki swarm earthquakes and crustal uplift-, Bull. Earthq. Res. Inst., Univ. Tokyo, 60, 147-177, 1985 (in Japanese with English abstract).

Shimazaki, K., Uplift in Ito and the 1978 Izu-Oshima-kinkai earthquake, Earth Monthly, 2, 137-145, 1980 (in Japanese).

Singh, S. K., Gravitational attraction of a circular disc, Geophysics, 42, 111-113, 1977.

Suzuki, Y. and N. Oshiman, A paradox in volcanomagnetism: disagreement between analytical and numerical estimates of geomagnetic changes due to an underground pressure nucleus, J. Geomag. Geoelectr., 42, 1291-1308, 1990.

Tada, T., On the anomalous crustal activity in the Izu Peninsula (2)-Relation between vertial and horizontal movements-, Programme and Abstracts, the Seismological Society of Japan (1983 Spring), 150, 1983 (in Japanese).

Takahasi, H. and M. Mori, Double exponential formulas for numerical integration, Publ. $R$. I. M. S., Kyoto Univ., 9, 721-741, 1974.

Tanaka, Y., H. Masuda, M. Kawamura, K. Ohchi, Y. Kato, K. Baba, and T. Yoshino, Surveys of geomagnetic total intensity with proton precession magnetometers on Aso Volcano (1977), in Report of the Joint Geophysical and Geochemical Observations (August-December 1977), ed. A. Kubotera, pp. 31-39, Kyoto Univ., Kyoto, 1978 (in Japanese).

Tsumura, K., Anomalous crustal activity in the Izu Peninsula, J. Phys. Earth, 25, S51-S68, 1977.

Tsuneishi, Y., Automatic electronic distance measurement on the Off-Ito swarm earthquakes and submarine eruption of July, 1989, J. Geogr., 99, 153-165, 1990 (in Japanese with English abstract).

Tsuneishi, Y., Continuous monitoring of crustal activity in east Izu Peninsula by automatic electronic distance measurement, J. Phys. Earth, 39, 131-139, 1991.

\section{APPENDIX}

\section{Magnetic Field of a Spherical Segment}

Consider a uniformly magnetized spherical segment as shown in Fig. Al. This is the upper portion of a sphere of radius $a$, centered at $(0,0, D)$ and cut by a plane $z=D-a+h$, whose magnetization is $\left(J_{x}, J_{y}, J_{z}\right)$. For the sake of simplicity, the observation point $\left(x_{0}, y_{0}, z_{0}\right)$ is assumed above the segment (i.e., $\left.z_{0} \leq D-a\right)$. Refering to the derivation process of the gravitational attraction of a circular disc (Singh, 1977), we obtain the magnetic potential of a circular disc. The magnetic field of a spherical segment can be simply given by integration from $z=D-a$ to $z=D-a+h$. Only the final expressions are reproduced here, which are analogous to a formula for magnetic field of a circular cone by Rikitake (1951). In the following, $\left(X_{k}, Y_{k}, Z_{k}\right)$ indicates 


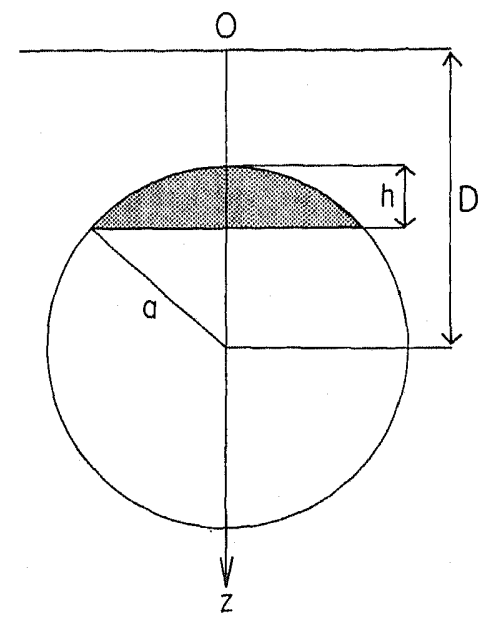

Fig. A1. Geometry of a spherical segment and coordinate system. The hatched portion of the sphere is uniformly magnetized. The $z$-axis is taken positive downward.

magnetic components due to the $k$-th component of the uniform magnetization $J_{k}$ :

$$
\begin{gathered}
\frac{1}{2 \pi J_{x}} X_{x}=\frac{x_{0}{ }^{2}-y_{0}{ }^{2}}{r_{0}{ }^{2}} F-\frac{x_{0}{ }^{2}}{r_{0}{ }^{2}} G \\
\frac{1}{2 \pi J_{x}} Y_{x}=\frac{2 x_{0} y_{0}}{r_{0}{ }^{2}}\left(F-\frac{1}{2} G\right) \\
\frac{1}{2 \pi J_{x}} Z_{x}=\frac{x_{0}}{r_{0}} H \\
\frac{1}{2 \pi J_{y}} X_{y}=\frac{2 x_{0} y_{0}}{r_{0}^{2}}\left(F-\frac{1}{2} G\right) \\
\frac{1}{2 \pi J_{y}} Y_{y}=\frac{y_{0}^{2}-x_{0}^{2}}{r_{0}{ }^{2}} F-\frac{y_{0}^{2}}{r_{0}{ }^{2}} G \\
\frac{1}{2 \pi J_{y}} Z_{y}=\frac{y_{0}}{r_{0}} H \\
\frac{1}{2 \pi J_{z}} X_{z}=\frac{x_{0}}{r_{0}} H \\
\frac{1}{2 \pi J_{z}} Y_{z}=\frac{y_{0}}{r_{0}} H
\end{gathered}
$$

Vol. 39, No. 1, 1991 


$$
\frac{1}{2 \pi J_{z}} Z_{z}=G
$$

where

$$
\begin{gathered}
F=\frac{1}{r_{0}} \int_{z_{1}}^{z_{2}} R(z) I(1,1 ; 0) \mathrm{d} z \\
G=\int_{z_{1}}^{z_{2}} R(z) I(1,0 ; 1) \mathrm{d} z \\
H=-\int_{z_{1}}^{z_{2}} R(z) I(1,1 ; 1) \mathrm{d} z
\end{gathered}
$$

and $r_{0}=\sqrt{x_{0}{ }^{2}+y_{0}{ }^{2}}, z_{1}=D-a, z_{2}=D-a+h . R(z)$ is the circular radius of the cross section at $z$, i.e.

$$
R(z)=\sqrt{a^{2}-(D-z)^{2}} .
$$

$I(m, n ; l)$ 's are called the Lipschitz-Hankel-type integrals and are defined by

$$
I(m, n ; l)=\int_{0}^{\infty} J_{m}(a t) J_{n}(b t) \mathrm{e}^{-c t} t^{l} \mathrm{~d} t .
$$

They are represented with complete elliptic integrals (Eason et al., 1955):

$$
\begin{gathered}
I(1,1 ; 0)=\frac{1}{k \sqrt{a b}}\left\{\left(1-\frac{1}{2} k^{2}\right) F_{0}(k)-E_{0}(k)\right\} \\
I(1,0 ; 1)=\frac{k^{3}\left(a^{2}-b^{2}-c^{2}\right)}{16 a k^{\prime 2}(a b)^{3 / 2}} E_{0}(k)+\frac{k}{4 a \sqrt{a b}} F_{0}(k) \\
I(1,1 ; 1)=\frac{c k}{4(a b)^{3 / 2}}\left\{\left(1-\frac{1}{2} k^{2}\right) k^{\prime-2} E_{0}(k)-F_{0}(k)\right\},
\end{gathered}
$$

where $F_{0}$ and $E_{0}$ are complete elliptic integrals of the first and second kind multiplied by $2 / \pi$ and $k^{2}=4 a b /\left\{(a+b)^{2}+c^{2}\right\}, k^{\prime 2}=1-k^{2}$. We should replace $a, b$, and $c$ in Eqs. (A.15), (A.16), and (A.17) with

$$
a=R(z), \quad b=r_{0}, \quad c=z-z_{0}(>0) .
$$

$F, G$, and $H$ are definite integrals of analytic functions. Hence integrals (A.10), (A.11), and (A.12) can be numerically calculated with the double exponential formula (Takahasi and Mori, 1974).

At $r_{0}=0$, formulas (A.1) through (A.9) become indefinite. Taking the limit of Bessel functions for $r_{0}$ approaching zero, we find closed form expression at $r_{0}=0$ :

$$
\frac{1}{2 \pi J_{x}} X_{x}=\frac{1}{2 \pi J_{y}} Y_{y}=-F_{0}, \quad \frac{1}{2 \pi J_{z}} Z_{z}=2 F_{0},
$$




$$
Y_{x}=Z_{x}=X_{y}=Z_{y}=X_{z}=Y_{z}=0
$$

where

$$
\begin{aligned}
F_{0}= & \frac{1}{4\left(D-z_{0}\right)^{3}}\left\{-\frac{1}{3}\left[X^{3 / 2}\right]_{X_{1}}^{X_{2}}+2\left(\left(D-z_{0}\right)^{2}+a^{2}\right)\left[X^{1 / 2}\right]_{X_{1}}^{X_{2}}\right. \\
& \left.+\left(D-z_{0}+a\right)^{2}\left(D-z_{0}-a\right)^{2}\left[X^{-1 / 2}\right]_{X_{1}}^{X_{2}}\right\}
\end{aligned}
$$

and

$$
X_{1}=\left(D-a-z_{0}\right)^{2}, \quad X_{2}=X_{1}+2\left(D-z_{0}\right) h .
$$

Vol. 39, No. 1, 1991 